\title{
Perceptual Dramaturgy: Swimmer (68)
}

\section{Pil Hansen}

[E]very act of perception is, to some degree, an act of creation, and every act of memory is, to some degree, an act of imagination.

\section{— Gerald M. Edelman and Giulio Tononi, A Universe of Consciousness ${ }^{1}$}

This essay proposes a form of perceptual dramaturgy: a set of tools that has been developed through the application of a cognitive lens to the craft of dramaturgy. I argue that theories of perception and memory can enable the dramaturg to work with some of the implicit dynamics of experience that precede both artistic choicemaking in the developmental process and the spectator's arrival at interpretation in performance. As the theoretical basis and tools of perceptual dramaturgy are introduced, I explore their application through the case of the devised solo piece Swimmer (68).

Swimmer (68) is an intermedial solo performance about a character's struggle to develop and maintain an autobiographical self by negotiating lived and mediated experiences from his past. Imagine an adult who has been isolated in a nonmaterial environment, recycling and integrating memories, since childhood. This is the character's (admittedly impossible) condition. Suddenly faced with an audience, he begins to sense and examine gaps in his reenactment of memories. Swimmer (68) is performed by the devisor Ker Wells, directed by Bruce Barton, and dramaturged by myself, with the sound artist Richard Windeyer and the video artist Cam Davis. In addition to the application of cognitive theory to the dramaturgical process, the production team took creative inspiration from cognitive ideas about subjectivity and autobiographical memory. These ideas were used to define principles that could be consulted as signposts rather than a set of strict rules.

The analytical demonstration of perceptual dramaturgy is divided into three sections that respond to the specific dramaturgical tasks and challenges of three

\footnotetext{
Pil Hansen is exploring cognitive layers of memory in dance and theatrical devising as a SSHRC postdoctoral fellow at the University of Toronto. She has worked as a professional dramaturg of dance, devising, and new circus in Scandinavia and Canada since 2002 and teaches dramaturgy at the University of Toronto. Current projects are Acts of Memory, Swimmer (68), and Vertical City II. Her articles are published in TDR: The Drama Review, Canadian Theatre Review and Peripeti, as well as the essay collections Space and Composition (Danish National Theatre School and Nordic Centre for the Performing Arts, 2005), Developing Nation (Playwrights Canada, 2009), and At the Intersection between Art and Research (NSU, 2010).
} 
developmental stages of Swimmer (68): (1) understanding the collaborators' habits of perception at the stage of project initiation; (2) proposing principles and sources of inspiration that can either challenge or establish connections between artistic approaches in the workshop phase; and (3) preparing for the final production phase by analyzing compositional possibilities with a focus on how they can be realized through the spectators' potential perception.

This essay joins a growing number of voices calling for the development of new dramaturgical functions and tools in response to the increased involvement of dramaturgs in contemporary "postdramatic theatre." Historically, and within established institutions, the dramaturg's job description has fallen into either production dramaturgy or new play development. When working on physicallybased performance that does not take its point of departure in a text or a preset choreographic score, this division of agency-between development and production - ceases to make sense. If there is a shift between development and production in such projects it is not from a text or a score to its realization; it tends to be from the generation of ideas and loosely interconnected performance material to the making of compositional choices. The devising dramaturg can benefit from drawing on both the process-oriented tools of developmental dramaturgy and the conceptual and analytical tools of production dramaturgy, but this expanded field of agency and orientation does not, in itself, provide solutions to the challenges of new dramaturgy. Physically-based work often aims to affect the spectators' sensory experience in ways that do not invite them to synthesize stimuli as dramatic structure, character, or meaning. In response to this characteristic, a need arises for tools to analyze and make strategic choices about the perceptual experience a composition facilitates.

Reflecting a growing awareness of these needs, the creative approach and analytical tools of perceptual dramaturgy were initially developed in 2007 and have subsequently been applied and adapted to the creation of new opera, theatrical devising, modern dance, improvisational events, new circus, and puppetry in Denmark, Sweden, and Canada. ${ }^{2}$ As I begin to discuss perceptual dramaturgy in the context of Swimmer (68), it is a matured generation of the approach and its tools that I turn to.

Initiated in a workshop in the summer of 2008, Swimmer (68) underwent further development in May and December of 2009, the latter period concluding with a work-in-progress performance. Final development and production, funded by the Toronto and Ontario Arts Councils, is scheduled for May 2011 in Toronto.

The performance material has been devised through physically-based improvisation and writing tasks and inspiration has been drawn from Wells's childhood memories, photos, news broadcasts, and movies from the late 1960s, including Fran Perry's The Swimmer (1968). At its current stage of development, the material includes thirteen scenes that alternate between two types of sequences. 
In one type of sequence, the character rests on a chair, immobile, and a voiceover states, "I have only had one dream. In the dream, I am in a room with no door. I am sitting in a chair, trying to remember something." ${ }^{3}$ The memory is expanded over several repetitions of the scene until the character physically, without speaking, opens a window and discovers water on the other side. The other, more dominant sequence is a series of associative explorations of childhood memories in fragments, including mediated memories. The character gradually begins to remember more and more situations of watching and listening to media, instead of predominantly weaving mediated actions and voices into his lived memories without the ability to fully differentiate. In the final scene, the character constructs a new autobiographical narrative from selected aspects of the memories explored throughout the piece. In this scene the character reenacts rowing a boat out onto a lake with his sister to see the moon on the same night that the first moon landing was broadcast. The moon is reflected on the water's surface and the character steps onto the reflection.

\section{Reflecting on Habits of Perception at the Workshop Stage}

At the end of the first developmental workshop in 2008, when I initially joined the project, the dramaturgical task was to help navigate the approaches, skills, and ideas in the studio. In general, a focus on the perceptual habits of the devisors can prove very useful at this stage of a devising project. ${ }^{4}$ If applied with the team's creative objectives in mind, cognitive theory about learning, perception, and memory can lead to strategies for creative development. When, for instance, long-time collaborators aim to break out of a pattern and discover new forms of expression, the dramaturg can help introduce interdisciplinary challenges, unfamiliar techniques, and new source material to push the artists beyond the repetition of habitual forms of perception and response. But in projects like Swimmer (68), where a combination of very different approaches seriously challenges each collaborator's skills and patterns of response, there may be a need for common principles to help the collaborators explore connections between their different approaches, and gradually adapt to each other's perceptual habits through the work. The dramaturg also needs to be critically self-reflective about how her own approach influences what she is attentive to in order to adapt and further develop her skills.

These strategies are informed by the implicit (i.e., unconscious) ways in which memory shapes our perception and response in the present and vice versa. Gerald Edelman and Giulio Tononi's theory of "the remembered present" offers a useful insight into such dynamics of perception and memory. ${ }^{5}$ When directing one's sensory registers toward a source of stimulus, an often prereflexive process of selection begins. As Edelman and Tononi put it, "[W]e extract the meaning or gist of a scene, rather than its innumerable and rapidly varying local details." 6 The different types of stimuli to which this selective attention gives a person access are processed within, transferred between, and returned to reciprocally connected 
areas of the brain. Each return, or in Edelman and Tononi's terminology "reentry," of information results in further selection, integration, and synthesis of stimuli. One achieves consciousness about a perception at the stage of this process when a large core of the brain is engaged in reentrant interactions. ${ }^{7}$ The chemical change in the synapses that allows neurons to "fire and wire" together during the process of perception is not easy to establish, but once it is established - and if it is maintained through frequent usage - it can be repeated efficiently. ${ }^{8}$ Studies into neurological activity and learning show that the neural activity decreases when the efficiency of performance increases. ${ }^{9}$ As in the case of motor skill acquisition, "The number and range of sensory inputs that are initially 'consulted' for conscious control and that can influence the performance are enormous, including many details and irrelevant stimuli." 10 The initial task of processing all available stimuli results in enhanced brain activity and renders the person conscious of details. As the skill is learned the inputs are restricted and the reentrant process of perception it involves becomes more selective and efficient. This efficiency can decrease brain activity to the extent where a large core of the brain no longer becomes engaged. The consequence is that the performance and the perceptual process it entails remain unconscious and become automated. ${ }^{11}$ Such automated perceptual patterns and responses are what I refer to as perceptual habits.

When memory enters the picture, it becomes clear that perceptual habits extend far beyond what is commonly understood as habitual routines. From the perspective of Edelman and Tononi's theory, memory retrieval is the ability to trigger and repeat a reentrant process. Memory is not retrieved from an archive of stored representations; rather, it is a dynamic process. ${ }^{12}$ As most of our automated perceptions reuse established reentrant processes, they are memories projected into the present, which gives rise to Edelman and Tononi's term "the remembered present." This implicit repetition of a perceptual process, however, is rarely pure as new stimuli are integrated and change the process each time it is reused in the present. In effect, "memory has properties that allow perception to alter recall and recall to alter perception." "13 If discrepant stimuli render this repetition dysfunctional, conscious attention is once again directed toward the task of processing a vast amount of sensory details. When the habit therefore is challenged, a process of either radically altering the learned behavior or learning a new skill begins. ${ }^{14}$

This theory provides the frame that I use when observing the habitual responses of actors in rehearsal. It also informs the previously mentioned strategies of disrupting repetitive behaviors, reducing hindrances that render the collaborators' habits dysfunctional, or - as in Swimmer (68)_-suggesting principles that can connect very different approaches to creation and performance. In the case of Swimmer (68), the task of identifying principles that could help Wells and Barton connect their approaches began with an attempt to understand these approaches in terms of what they do: what they make each collaborator attentive to and how 
they produce different responses to shared source materials and ideas. The brief examples offered here derive from exchanges with Wells and Barton. ${ }^{15}$

From the outset, Wells brought to the rehearsal studio techniques of actorcentered and physically-based devising that draw upon the legacies of Grotowski and the Odin Theatre, techniques that are inherently suspicious of New Media. Wells's devising process usually starts with the creation of a piece of physical material, drawing on associations from a chosen source of inspiration. Later in the process, the created piece will be taken apart and layered with other material. Regardless of whether or not Wells's source of inspiration is autobiographical, his physical response to stimuli always involves some investment of his sense of self:

$[\mathrm{M}] \mathrm{y}$ choices of how to move and what action to choose to represent a certain moment or incident are deeply and constantly informed and influenced, both consciously and doubtless unconsciously, by memories of my own life, which flit unbidden into mind and body when I activate my creative imagination. ${ }^{16}$

In order to keep this work in process, perceptions and associations are channelled into physical responses. The creative process is reflected upon, but the desire to analyze sensorimotor experience and prematurely arrive at an interpreted "product" is suppressed.

Barton is both an artist and a scholar, specializing in theatrical devising and theory of intermediality. Like Wells, Barton is invested in the open process, though his strategy differs. He entertains multiple potential interpretations of performance material and its theoretical framework simultaneously and considers their ongoing revision and competition part of the process. When first presented with Wells's source materials for Swimmer (68), Barton's attention was on the media of photographic, televisual, radiophonic, and cinematic sources and his artistic inquiry became about the ways in which these media affect a person. This focus led him to challenge the concept of self that Wells's approach depends on and argue that in a thoroughly intermedial world,

Not only do we have the sense that, as the center of our own intermedial universe, we somehow possess and contain the storm of data to which we are subjected every day of our lives. At the same time, inevitably, we are faced with the unavoidable evidence of our own surrender to, our own consumption by, the spectacle of media, which doesn't merely influence and affect, but in fact contributes to and makes coherent our understanding of our selves as "selfs."17 
When this theoretical perspective is followed through to its practical consequences in the rehearsal space, Barton does not need to begin with a physical response to media, as Wells does; he can introduce media that acts upon the performer, and then begin to discover how it may or may not contribute to the performer's experience of embodiment and self.

Though far apart, it is possible to intersect these approaches. In fact, when pushing a bit beyond the most immediate responses, the observation that served as the impetus for the project can both facilitate connection and make productive use of the differences. Wells was intrigued by an experience of uncertainty about the source of some of his childhood memories. It was unclear to him whether they reflected lived experience or media images he saw as a child; and his attempt to differentiate by recalling the moment of originally watching what he suspected to be mediated memories did not produce a stronger sense of certainty. Revisiting an example of this observation, which concerns one of his source materials for the project, Wells stated:

In my memory of my first viewing of The Swimmer, I am watching it beside a swimming pool, but I think that in fact what I am remembering here is the summer afternoon beside a pool in suburban Winnipeg, when someone, an older friend, first told me about the film .... Memory is tricky. ${ }^{18}$

Burt Lancaster's character in The Swimmer decides to make his way from a pool party to his home through the adjacent private and public pools of his rich neighborhood. ${ }^{19}$ On this journey, his strong rapport, self-confidence, and physical health gradually deteriorate as he, piece-by-piece, retrieves memories of his personal and economic ruin. For the production team, Wells's confused memory of this movie became a central source of inspiration for a theatrical exploration of whether one can differentiate between mediated and lived memories. Not surprisingly, given their different approaches, Wells and Barton had distinct understandings of how this question could be addressed in Swimmer (68):

[Wells] was initially invested in the character ultimately being successful at solving the riddle and finding the "one true memory" amidst the storm of media distraction. For my part, I toyed with the idea that the character might have to come to terms with the reality that he was, in fact, all media, that he had no existence outside of the patchwork of media sounds and images that made up his memories. ${ }^{20}$

The evolving understanding of the different approaches in the rehearsal space 
after the first workshop in 2008 suggested that the shared interest in Wells's initial observation was not enough; there was a need for a common understanding of the observation that is transferable — as a set of principles - to the relationship between the actor's embodiment, the character, and the media in Swimmer (68).

\section{Proposing Principles (of Memory and Self) to Connect Diverging Approaches}

When developing ideas for transferable principles, I revisited the first performance material Barton and Wells presented to me. In this material (which since has been developed into scenes 2 and 4), Wells runs onto the stage through the audience. Dripping wet and wearing swimming trunks, he dries himself with a towel. Then he pulls on a pair of long pants and turns to look at the audience while raising his muscular arms and saying:

Look at me.

Look at me.

I eat like a horse and I don't put on an ounce. I'm sleeping well for the first time in months. You don't know what's coming down the tube, but the important thing is ...

He notices something on the floor and bends to pick it up. It's a watch. He holds it to his ear. He puts it in his pocket.

... the important thing is watch for the signs, trust your instincts, and be at peace with yourself . . .

God! What a wonderful ... what a wonderful ...

What is it, I had it just a minute ago.

[...] He takes the hands of a spectator and pulls her towards him.

Let me look at you.

You look sensational. Is that a new suit?

God it's great to see you. What a vision. ${ }^{21}$

Wells proceeds to pretend that he is slapped by the spectator and mumbles reassuringly to himself that, "[I]t's ok, it's ok, " while touching his face. He turns suddenly to pursue a fleeting image of Burt Lancaster in swimwear and there is a splashing sound, as if Wells had stepped into water. (Note: the play-text excerpted here is used to record words and key actions or movements as the devising progresses).

When watching this material it seemed to me that the character is trying to confirm his self at multiple levels - from the most basic sensorimotor experience of self involved in the sensation of water and touch to a more cognitively synthesized autobiographical self. As the next scene delves into the telling of childhood stories, the most obvious level of self-maintenance I witnessed is the ongoing reactivation of the episodic long-term memories that support the character's autobiography. ${ }^{22}$ 
Yet Wells's almost intimidating physical presence in this opening scene also reflects Lancaster's attitude and activities in the early scenes of The Swimmer. The character's episodic memories are infused with mediated components in ways that, when confronted with an audience, generates curiosity and confusion about who he is.

When entering the second workshop in 2009, it was unclear to the creative team why the character is exploring memories, how he is exploring them, or to what the exploration might add up. Based on my observations, I suggested that answers to these questions could be discovered through the neurobiologist Antonio Damasio's theory of autobiographical memory. Damasio argues that "the autobiographical self arises from the core self." ${ }^{23}$ The core self is a basic experience of subjectivity that emerges repeatedly, but seamlessly, in response to sensorimotor exchange with an environment. ${ }^{24}$ The states that make up the core self are processed in both short-term and long-term memory and become the facts and episodes that are the basis of the autobiographical self. A person engaged with his environment would automatically sustain an illusion of core self continuity and develop an autobiographical self from new experiences. ${ }^{25}$ The memories of the autobiographical self are, in turn, recycled as parameters that influence choice behavior while in core self exchange in the present; ${ }^{26}$ and through that recycle these memories become confirmed and renewed. ${ }^{27}$

Thinking about Swimmer (68) from this perspective, I wondered how a grown man's autobiographical self would be affected if he had been isolated in a nonmaterial environment and hindered from engaging with his environment since childhood. The character of Swimmer (68) recalls and explores only memories and media images from the year of 1968, when Wells was six years old. What if the character had not been able to generate new core self experiences since then and was limited to recycling these memories? As Barton subsequently stated in a performance presentation at a Canadian Association of Theatre Research conference,

[It became] apparent to us that what our character is desperately attempting to assert is his autobiographical self, but that he has too few core self experiences to support that assertion .... Each scene became a heroic effort to compensate for his meagre store of embodied memories through resorting to the often vivid memories of mediation that seemed to bridge the gap. ${ }^{28}$

From a cognitive perspective - and if we imagine that these memories are recycled within the closed circuit of the character's unnatural condition-the reentrant process of perception and memory could result in the integration of lived and mediated memories. The difference, however, between the lived memories and memories he has experienced through media, which he cannot fully erase, is that 
the lived memories derive from his own fully embodied, core self experiences while the mediated memories do not. The character may have embodied memories that reflect the relation between a TV or radio and his body in the situation of taking in the media, but he would not have such memories of the sounds, images, and actions experienced through the media. Even if we were to turn toward Stamenov and Gallese's popularized theory of the "mirror neuron system" and hypothesize that a moving body in a motion picture may trigger the viewer's sensorimotor memory of similar movements, it does not generate a novel sensorimotor experience. Rather, the embodiment triggered would feed off a lived experience from the more distant past. ${ }^{29}$ When revisited by the character, the mediated memories are merely secondary channels to fully embodied experience; they are not the source of the experience. If the character never were an accomplished swimmer, then he would not be able to fully mirror Lancaster's swimming.

When understood from this perspective the character is unwittingly reactivating memories in the attempt to generate core self states and maintain an autobiographical self. The discussed difference between the lived and mediated memories, however, leaves detectable gaps and discrepancies which, when explored, cause doubt about the source of the memories. These possible explanations made us situate the character in the previously named isolated condition. Note that this condition is based on Wells's own doubt about the source of his memories. Wells's discomfort with New Media and his attempt to differentiate between the mediated and the "real" in the initial stage of the project feeds the character's exploration of memories. The emphasis on the sensorimotor aspect of the memories and the experience of embodiment resonates with Wells's creative approach and provides him with means to apply his skills within the otherwise unfamiliar performance vocabulary of intermedial work. In complementary ways, Barton's approach makes it possible to weave mediated material into Wells's devising process and arrive at an integrated construction of the character's autobiographical self: a construction that is sufficiently believable and involves enough embodied memory to offer the character a kind of life support.

\section{Analyzing Compositional Possibilities as Potential Perceptual Paths}

In preparation for the final production of Swimmer (68) in May 2011, the dramaturgical task shifts from developmental navigation to the identification of compositional problems and possibilities within the material developed to date. Drawing on the accumulated knowledge of the creative process and approaches discussed above, the analysis of the generated material needs to focus on two interrelated perceptual paths: one is the character's attempt to recycle memory as present perception; the second is the audience's potential experience of that attempt. To analyze the first path, it is necessary to look at how mediated and lived memories are combined in practice, that is, how the character engages them and explores the 
combinations within the performance material and, ultimately, how he reacts to this experience. The second path is addressed here by asking what aspects of the performance the audience's attention is drawn toward, how connections between such aspects are established through the spectators' perception, and to what effect. While the first path is specific to the subject material and ideas of Swimmer (68), the second path is always addressed when analyzing compositional possibilities as perceptual dramaturgy. In very general terms, the necessary material and principles to facilitate both the character's and the audience's perceptions were present in the work-in-progress performance in 2009 , but neither path had been fully realized. The goal is, thus, to identify compositional strategies that can lead to production solutions when explored in practice.

Because Swimmer (68) is created through a process of generating, layering, and combining material without the mould of a pre-imagined coherency or dramatic journey, the resulting creation is highly interspliced. The compositional challenge is not only to identify and map possible connections within the material, but also to predict the performative effect they may bring about.

Since the tools that dramaturgs are trained to use (directly or indirectly) focus on meeting audience expectations of more conventional structures, it is necessary to become aware of this tendency and bring into focus the perception of sensory details that is otherwise forgotten on the route to dramatic synthesis and yet is central in most approaches to physically-based devising. This can be done by distinguishing between the principles that organize human perception into meaningful units (such as the logics of linearity, causality, and coherency) and the impressions of sensory details that are organized through these principles. Endel Tulving's distinction between episodic and semantic systems of long-term memory is useful, particularly when related to the sensory registers and short-term memory described in Atkinson and Shiffrin's classic memory system. ${ }^{30}$ The term "semantic memory" refers to synthesized, organized, and durable knowledge about the world, while the "episodic memory" is the memory of episodes and situations that often involve physical or verbal action. The impression of sensory details (e.g., the color or movement of an object) are held for a short duration in short-term memory, unless they become the focus of attention and further processing in long-term memory (e.g., when learning). Awareness of this process is useful in identifying moments when the spectator is encouraged during performance to direct her attention to details, such as singular sounds or pitches, objects and their qualities, movements or gestures. All three systems of memory can be used to categorize potential performance materials based on an assessment of whether they are likely to be processed and remembered as sensory detail, episodic situations, or semantic logic. The result is both an expanded field of orientation and an overview of the components that have the potential to be memorable.

In order to better understand how segments of performance material become 
connected through the spectator's perception, I return to Edelman's concept of "the remembered present." If we accept his claim that new stimuli tend to reactivate and merge with past perceptions (i.e., memories) during the reentrant processes, then it is possible that the repetition of details in different parts of a performance may create connections for the spectator simply by triggering the same perceptual process.

When considering the types of effect such perceptual connections bring about, I draw upon the previously discussed difference between implicit and explicit reentrant processes. To understand this difference in practical terms, I developed the concepts of implicit assimilation, iterative association and adapted the concept of montage collision. ${ }^{31}$ Assimilation is achieved when the remembered perceptual process is repeated almost seamlessly in the present. When an experience is identified as an association, the perceiver usually has a definite, if unclear, sense of small discrepancies between the connected elements - a sense that renders conscious part of an otherwise implicit perceptual process. The gradual adaptation to these differences may result in iterative change of a perception. By montage collision I refer to instances where repeated material is inserted into contexts that render the repetition of a reentrant process dysfunctional; contexts that differ so significantly from the repeated material that the perceptual process it reactivates is breached. This also occurs when a pattern of repetition disappoints expectations. Such breaches force the spectator to consciously reorient expectations by focusing on and discovering new ways of organizing sensory details. This application of cognitive theory enables me to hypothesize about the potential connections and effects within the performance material that the interpersonal mechanics of perception can enable the spectator to make. ${ }^{32}$

The simplest way to use these principles (i.e., categorization with reference to the sensory, episodic, and semantic systems, the creation of connections through repetition, and the range of possible effects) when analyzing the perceptual dramaturgy of a composition is to work through the following steps: First, note repetitions in the material and color code them in the categories of sensory details; episodic actions, relations, and situations; and semantic meaning or logic. Subcategories that can help the dramaturg develop a project-specific focus are drawn from the collaborators' approaches and interests. When a net of repeated or similar material has been identified, the next step is to estimate whether the noted repetitions have the power to generate connections. Given the fact that perception and attention are highly selective, primed or foregrounded details are more likely to be recognized by the audience. ${ }^{33}$ Once this assessment has been made, the effect of the connections can be addressed: do they affect implicit assimilation, iterative association, or montage collision? A final step is to summarize the ways in which the work generally seeks to affect its audience and use it as a parameter for compositional choice making.

When applied to Swimmer (68), the analysis of potential perceptual connections 
and effects can help identify issues and develop strategies for the realization of the two perceptual paths. As previously mentioned, the devising process has produced a highly interspliced (and somewhat interconnected) performance material: a large number of words, phrases, and movements are repeated in multiple scenes. Not all repetitions, however, are likely to register with a spectator or help facilitate the two perceptual paths. The analysis can be used to weed out some of the less useful repetitions and strengthen the ones that can support the character's exploration of memories, reveal the discrepancies caused by the difference between lived and mediated memories, yet produce a repertoire of repeatable and integrated experiences that offers the character the choice of constructing an autobiography in response to his dilemma - an autobiography that explains his condition. In the following example, repetitions are extracted from a single scene and discussed within the sensory, episodic, and semantic categories, respectively. A selection of these repetitions is then traced to their reoccurrences in other scenes, and their ability to generate connections and effects are discussed with the aim of identifying problems and suggesting possible strategies.

In scene 7, the character engages remembered fragments of an episode with his sister that are triggered by the memory of a photograph. The following telling moves along a stylized physical score, and the underscored text signals material that is repeated elsewhere in the piece.

In the foreground there's a tricycle, tipped on its side, (look up) half out of the frame. As if the rider has just jumped off it. For a long time I thought she was the rider-that our parents had just asked her to sit for a photo, and she dropped the trike and half-sat on the chair and they took the picture.

(Starting to reach down)

But I think it was me that dropped it. Me that let go. I can feel a weight, falling from my hands. I can hear a wheel turning, ticking, as she moves away. I try to reach her, run after her.

(Throw and run US)

(stop USC) Now there's a rushing sound.

(look to $S R$ ) Ah. Sprinkler's going.

(At SR wall position, with face against it) That's why I'm wet.

(go to DSC, hand out) Hands in the water.

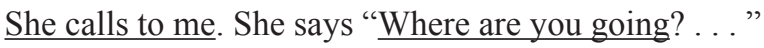

As the scene continues, statements such as, "Where are you going?" "I can't breathe, I can't hear," and "take my hand," are interspliced with remarks, cheering voices, and expressions of alarm from a 1968 political campaign. The remarks are loud, in Wells's voice, and come from the speakers of a 1960 s television set: $^{34}$ 
It's so cold.

Face up like this, eyes half-closed. Sleepy boy.

The wheel has stopped ticking, and when she calls me, I can hear it all, except the name. (Hand to face) The sprinkler sprinkles over it, every time.

But I can see her calling me through the water.

Where are you going, name? Where are you going? . .

He has finished the physical score standing beside the chair with his head resting on the towel, which is draped over the back of the chair, as if it were a pillow. His eyes flutter and then close as if he is asleep. As he sleeps, an image of Lancaster from The Swimmer appears, flickering on the US wall behind him. His eyes snap open, and the image disappears. ${ }^{35}$

Attention to repeated sensory details that potentially could support the character's experience of core self and embodiment is fairly strong in this scene. His attempt to engage the sensorimotor aspect of his memories is triggered by mediated components, but his engagement with the mediated memories does not differ from the lived ones in a consistent way that allows the spectator to perceive the difference and begin to experience the character's problem.

The character names some of the sensations involved in the episode he is trying to recall: the ticking sound, the feeling of water on his skin, the sensation of touch, eyes closing. At the same time the actor's stylized movements proceed in unbroken flow through some gestures that could reflect his physical memory of the situation he describes, along with others that seem unrelated. Though the underlined terms and concepts are repeated elsewhere in the material, many of the accompanying movements are only used in this scene. Given that it is the lack of direct embodiment that makes the character's mediated memories different from his lived ones, the described disconnect between the spoken and physical part of his memory recall could be used strategically to share the difference with an audience. It would, however, only work if the opposite principle is applied to the lived memories. At present, the spectators are repeatedly invited to direct their attention toward sensory details through the character's engagement with them, but the seemingly unrelated physical actions and high volume statements from the TV may, in turn, diffuse their perception. As a consequence details may not register sufficiently to establish connections to repetitions elsewhere. This issue could, in part, be addressed by establishing a more consistent principle for the relationship between terms and movements.

The scene has the following four combined episodic layers: (1) the explicit exposure of the character's act of remembering the photograph; (2) the fragments of 
the recalled episode with his sister, including the situation in which the photograph might have been taken; (3) the 1968 political campaign; and (4) the act of calling for his sister. Out of these episodes the act of remembering, the attempt to call his sister to him, and the relationship to the sister are repeated in different forms throughout the material. Although singular sensory gestures from the election material are repeated elsewhere, the material is so interspliced and fragmented that it cannot establish perceptual connections within the episodic category.

The primary invitation to make semantic sense of the material comes from repeated indications that the character is trying to remember something with great difficulty. The fragmented and interspliced characteristics of the scene can, in part, be explained by these "clues." Another possibility is the narrative logic of the character's search for his sister, including foreshadowing that something unfortunate might have happened between them.

Sensory details from scene 7 are repeated in and connect with three other scenes: scene 4 , which is the previously quoted scene where the character takes a spectator's hand and pulls her toward him; scene 5, a tale of leaving his sister behind, sneaking into the TV room at night, and watching the walls close in on a TV character; and scene 13, in which our character pieces together an autobiographical story or explanation by recycling details from previous scenes. All of the details in scene 7 that are repeated elsewhere do also occur in scene 13, though never in exactly the same way. This connection is unique to scene 7 and makes the scene central to the perceptual dramaturgy of the piece.

To offer an example of how connections and their effects can be traced, I will consider the details of "hand to face/touch face/slap" and "eyes close/closing." In scenes 4 and 13 the sensory touch contributes to an episodic act: pretending to be slapped by the spectator or being slapped by his mother before he ventures out in the boat. The two slaps are both memorable because of their sensory impact and position in the episodes, and, thus, it is likely that the spectator will connect them. They are not, however, equal. While the mother's slap offers an explanation for the earlier spectator interaction, the spectator interaction is more foregrounded and, therefore, haunts the mother's slap. We cannot know which incidence affects the character's memory of the other. This iterative association (which generates a montage collision in the episodic and semantic categories) does not occur when the touch is repeated in scene 5 and scene 7 . In these scenes the character brings his hands to the part of his face that was slapped by the spectator. This touch, however, is unrelated to the other details and actions within the two scenes; these "touches" seem to be spliced in fragments that hardly register and, thus, are unlikely to be associated with other repetitions. If the slaps were fully integrated into the two scenes (as the spectator's slap) they would register more and could generate additional associative and iterative connections. This type of connection would not only be made through the spectator, it would also allow the spectator to experience 
the recycling dynamic of memory which the character is exploring. Therefore, once the spectator arrives at an understanding of the issue of memory in the piece it would be a reflection upon her own experience as well as a logical synthesis of the character's experience.

The repetitions of the sensory detail "eyes close/closing" are all emphasized, but very different. In scene 5 , the character describes a childhood experience of watching walls closing in on a character on TV. In scene 7 , he closes his eyes after failing to reach his sister. The beginning of scene 13 differs again, as the character closes his eyes in the cinema because an action movie becomes overwhelming. The different types of "closing" noted here are so different that they may not have the power to generate connections as they currently stand; however, the integration of a few assimilating or associative repetitions could address part of this issue by placing "closing" in focus as a pattern of perception before collision occurs. Another, but I think important, observation involves the end of scene 13 where the character "remembers" stepping onto the moon's reflection on a lake's surface at night. If an associative pattern of connections between the "closing" details is established, then it could be all the more effective to cut a spoken repetition of "eyes closing" in this scene and instead develop a physical "closing in" of the environment and a final "closing of his eyes" at the end of the play.

At present, the spectator knows of the character's doubt about the source of his memories, but they are not given sufficient opportunity to experience the nature of his dilemma. Perhaps a solution lies in clearer attempts to relive the aspects of the memories that allow him to recycle fully embodied experiences. Similarly, one could try to break up the stylized movements with pedestrian gestures and pauses that relate to the "lived" details of the play-text. This strategy would be particularly effective if it were matched with the previously described strategy of consistently disconnecting movements and descriptions of mediated memories. The integration of "lived" words and movement would reveal the character's attempt to recycle memories, while the disconnections would enable spectators to experience the breaking point of this attempt. If the gradual increase in memories of watching the media (as opposed to considering the mediated content personal experience) is caused by these breaking points, then the creative team may also discover a related reason for the character's final choice.

It is much easier to make visible the process of constructing a believable autobiographical self than it is to reveal that the construction is a product of the character's failure to fill in the gaps in his lived memories with mediated content. A step toward a solution to this challenge is to ensure that the constructed autobiography cannot fully explain previous occurrences of the recycled details.

If the potential perceptual paths and effects outlined here are, indeed, what the creative team wishes to achieve, then the analysis of perceptual connections can be used to determine how the full network of recycled details can be expanded and 
tightened to establish the character's search and self construction.

\section{Conclusion}

Dramaturgical strategies of composition are developed from hypotheses about an audience's experience in a future performance situation. Perceptual dramaturgy provides unprecedented tools to advance and further qualify such hypotheses. Instead of applying the principles of predetermined dramaturgical models or targeting the intellectual interpretation that a spectator might arrive at after leaving the theatre, perceptual dramaturgy makes it possible to both hypothesize and strategize about the complex perceptual experiences that given creative material can facilitate in performance. Although these tools can be applied broadly to theatre, performance, and dance, perceptual dramaturgy is particularly effective in projects like Swimmer (68) where the principles used to facilitate a devising process directly impact the development of compositional strategies. In such projects, the perceptual dramaturgy of creation invests in, challenges, and cross-pollinates the habits of the artists involved and the perceptual dramaturgy of composition can potentially invite the spectator to direct her attention differently and discover new ways of synthesizing and responding to sensory stimuli.

\section{Notes}

1. Gerald M. Edelman and Giulio Tononi, A Universe of Consciousness: How Matter Becomes Imagination (New York: Basic, 2000) 101.

2. Perceptual dramaturgy was developed through three cycles of practice-based experimentation with cognitive theory. This work was completed with four professional dramaturgs at the University of Copenhagen (Denmark) in 2007 as part of my doctoral dissertation. The approach has been applied and adapted to the following projects: Aetyde (choreographer Ari Rosenzweig, dancers Ari and Hagit Rosenzweig and Fernanda Echenique, at Dansescenen, Copenhagen, Denmark. 2002); Frontiers (choreographer and performer Sara Gebran, music by DJ Ñ, video by Michael Bing, dramaturgical input from Pil Hansen, at Kaleidoskop Teater, Copenhagen, Denmark, 2004); Moving Stage Lab (a devising workshop designed by Bruce Barton and Pil Hansen for the Danish Chapter of the International Theatre Institute, Copenhagen, Denmark, July 2006); EX:changing Memories of Movement (an improvisational exchange between dancers from Scandinavia and the Middle East, initiators Pil Hansen and Sara Gebran, at the Dramatiske Institutet and WELT, Stockholm, Sweden, February 2007); Det Kinesiske Spoegelse (a new opera performance, The Chinese Ghost, libretto by Gritt Uldall-Jessen, dir. Helene Kvint, text dramaturg Jette Lund, at Musikteatret Plex, Copenhagen, Denmark, April 2008); Vertical City I (a new circus workshop production: dir. Bruce Barton, dramaturg Pil Hansen, devisors Frank Cox-O'Connell and Marc Tellez, aerialists Lorie Le Mare and Diane McGrath, music by Ann Stadlmair, at Harbourfront Performing Arts' HATCH program, Toronto, Canada, spring 2008); Swimmer (68) (a devised performance, dir. Bruce Barton, perf. Ker Wells, dramaturgy Pil Hansen, sound art by Richard Windeyer, video Cam Davis, at Glen Morris Studio Theatre, Toronto, Canada, forthcoming May 2011); Vertical City II (a new circus and puppetry workshop by dir. Bruce Barton, dramaturg Pil Hansen, aerialist Lori Le Mare, puppeteers Ann Powell, David Powell, and Marcus Jamin, at University of Toronto, Canada, July 2010).

3. Ker Wells with Bruce Barton, Swimmer (68), 2009, MS, 1.

4. For extensive discussions of this topic see my articles: "The Reflection Forums of Moving Stage Lab," CTR 135 (Summer 2008): 58-60; "Dramaturgisk Navigation med Danske og Candiske Redskaber" ("Dramaturgical Navigation with Danish and Canadian Tools"), Peripeti 10: Dramaturger og Dramaturgier (2008): 61-74. See also Hansen and Bruce Barton, "Research-Based Practice: Situating 
Vertical City between Artistic Development and Applied Cognitive Science," TDR 53.4 (Winter 2009): 120-36, and Hansen and Barton's "Embodying Mediated Autobiography," panel on Cognitive Studies and Embodiment in Theatre and Performance, Association for Theatre in Higher Education Annual Conference, Los Angeles, August 2010.

5. Edelman and Tononi 102-12.

6. 141 .

7. $139-40$.

8. The ability of the neural connections, or synapses, to change in strength depending on whether they are used or not is generally referred to as synaptic plasticity.

9. Among Edelman and Tononi's examples is a PET study from 1992 measuring cerebral glucose metabolic rates in young subjects who were learning to play the computer game Tetris (60).

10. 59 .

11. $57,187-88$

12. 101 .

13. 101 .

14. A classic example is the attempt to work on a keyboard with an unfamiliar layout. In such a situation conscious attention is drawn to the motor control of fingers, the position of the individual keys, and the letters on the screen until the skill of typing has been adapted (retrained and once again rendered implicit) and conscious attention can be reserved for the meaning of full sentences.

15. These exchanges eventually resulted in a joint presentation by Bruce Barton, Ker Wells, and myself, "Navigating Memory: Dramaturgical Strategies and Swimmer (68)," The Canadian Association of Theatre Research's annual conference (Montreal: Concordia University, May 2010). In experimental and/or interdisciplinary contexts it can be useful to prioritize a more detailed analysis of the collaborators' perceptual habits than offered here in order to facilitate exchange and productive contamination. See Hansen and Barton, "Research-Based Practice" for an example of a more detailed analysis.

16. Wells's contribution to the conversations that developed into Barton, Wells, and Hansen's conference presentation "Navigating Memory."

17. Barton's contribution to Barton, Wells, and Hansen.

18. Wells's contribution to Barton, Wells, and Hansen.

19. The Swimmer, dir. Frank Perry, perf. Burt Lancaster (Columbia Pictures, 1968).

20. Barton's contribution to Barton, Wells, and Hansen.

21. Swimmer (68) 1-2. A more developed version of the play-text is forthcoming in Canadian Theatre Review (145 [Winter 2010]) on "Memory."

22. For a discussion of autobiographical self-continuity and maintenance, see Donna Addis and Lynette Tippet, "The Contributions of Autobiographical Memory to the Content and Continuity of Identity: A Social-Cognitive Neuroscience Approach," Self Continuity: Individual and Collective Perspectives, ed. Fabio Sano (New York: Psychology, 2008) 55-70.

23. Antonio R. Damasio, The Feeling of What Happens: Body and Emotion in the Making of Consciousness (New York: Harcourt Brace, 1999) 18.

24. 172 .

25. $174-75$.

26. 217.

27. Addis and Tippet 73. I have also been informed by the following: Alan Baddeley, "The Concept of Episodic Memory," Episodic Memory: New Directions in Research, eds. Alan Baddeley, Martin Conway, and John Aggleton (New York: Oxford UP, 2002), 1-10; Alan Baddeley, Essentials of Human Memory, 2nd ed. (London: Psychology, 1999); and Elizabeth Styles, Attention, Perception and Memory: An Integrated Introduction (New York: Psychology, 2005).

28. Barton, Wells, Hansen, "Navigating Memory: Dramaturgical Strategies and Swimmer (68)."

29. Maxim I. Stamenov and Vittorio Gallese, eds., Mirror Neurons and the Evolution of Brain and Language (Amsterdam: John Benjamins, 2002).

30. See Endel Tulving, "Episodic Memory and Common Sense: How Far Apart?," Episodic Memory: New Directions in Research, eds. Alan Baddeley, Martin Conway, and John Aggleton (New York: Oxford UP, 2002) 269-88; and R. C. Atkinson and R. M. Shiffrin, "Human Memory: A Proposed System and its Control Processes," The Psychology of Learning and Motivation: Advances in Research and Theory 2 (1968) 89-195.

31. The concept of collision is inspired by Sergei Eisenstein's theory of film montage. Steering away from the principles of composition in both the dramatic and visual arts, Eisenstein aimed to compose cinema through the spectator's perceptual reaction to the collision of individual montage principles. Among the principles he named for the montage of images are metric intervals, rhythmic movement within the frame, and emotional tone. Listing a number of collision effects, Eisenstein offers 
the following example: "The transition from metrics to rhythmics came about in the conflict between the length of the shot and the movement within the piece" "Methods of Montage," Film Forum: Essays in Film Theory, ed. and trans. Jay Leyda [New York: Harcourt, 1949]: 79).

32. The spectator's orientation and attention is, of course, not only shaped by cognitive biology and the stimuli offered by the performance. Each spectator brings to the theatre learned perceptual practice, habit, and memories that the dramaturg cannot predict. She can, however, return to existing tools of discourse analysis or hermeneutical context analysis to arrive at knowledge about collective memories and conventions of understanding which may take part in the individual's learned perceptual practice.

33. That is, unless, a "contract" to pay attention differently has been established. The notion of building and breaking "contracts" with the audience about what to expect is inspired by the Canadian dramaturg Kate Lushington's approach as discussed in my essay, "Dramaturgical Strategies: Articulations from Five Toronto-Based Theatre Artists," Developing Nation: New Play Creation in Canada, ed. Bruce Barton (Toronto: Playwrights Canada, 2008) 169-84; 177.

34. The soundscape and the words spoken by Wells are taken from a recording of Robert F. Kennedy's 1968 victory speech and assassination. The context and manipulation of these sounds, however, render them largely unrecognizable.

35. Swimmer (68), 5-6. 